Article

\title{
A PGIS-Based Climate Change Risk Assessment Process for Outdoor Recreation and Tourism Dependent Communities
}

\author{
Karly Bitsura-Meszaros ${ }^{1}$, Erin Seekamp ${ }^{1}{ }^{\mathbb{D}}$, Mae Davenport ${ }^{2,3}$ and Jordan W. Smith ${ }^{4,5, *(\mathbb{C})}$ \\ 1 Department of Parks, Recreation and Tourism Management, NC State University, Raleigh, NC 27695, USA; \\ meszaros.karly@gmail.com (K.B.-M.); elseekam@ncsu.edu (E.S.) \\ 2 Center for Changing Landscapes, University of Minnesota, Minneapolis, MN 55108, USA; mdaven@umn.edu \\ 3 Department of Forest Resources, University of Minnesota, Minneapolis, MN 55108, USA \\ 4 Institute of Outdoor Recreation and Tourism, Utah State University, Logan, UT 84322, USA \\ 5 Department of Environment and Society, Utah State University, Logan, UT 84322, USA \\ * Correspondence: jordan.smith@usu.edu
}

Received: 9 May 2019; Accepted: 31 May 2019; Published: 14 June 2019

check for updates

\begin{abstract}
Climate change is affecting human and geophysical systems in a variety of complex and interdependent ways. For nature-based tourism-dependent communities like those along the North Shore of Lake Superior in Minnesota, impacts to the region's abundant natural resources can subsequently affect the livelihoods of individuals who depend upon those resources to provide essential ecosystem services and support the region's economy. Many of the area's natural and outdoor recreation resources are collaboratively managed, making cooperation essential to address climate change impacts. In this study, we engaged North Shore stakeholders in a climate change risk assessment process through an exploratory application of participatory geographic information systems (PGIS). Stakeholder involvement allows for the co-production of science to deliver locally-relevant data and information. Involving stakeholders through a PGIS-based climate change risk assessment process allows locally-relevant data and information to be represented and visualized spatially. We used PGIS focus groups, as well as pre- and post-surveys, to solicit stakeholders' perceptions of risk thresholds (i.e., the time scale of impacts) and climate-related risk severity to sites with built infrastructure, natural amenities, and recreation and tourism destinations. The stakeholders' knowledge, as well as their commitment to their communities and local environments, influenced general perceptions of region-wide climate-related vulnerabilities. The PGIS exercises generated important discussion among stakeholders and shed light on how to more efficiently collect spatially-explicit data and information from stakeholders that can be used to inform mitigation and adaptation efforts.
\end{abstract}

Keywords: resilience; vulnerability; adaptation; community capacity; evaluation; participatory research

\section{Introduction}

The warming of Earth's climate system is a worldwide phenomenon. However, different regions around the globe are expected to experience different magnitudes of change [1]. Shifts in average daily temperatures and precipitation rates will be more dramatic in some areas relative to others. As such, regional variation in the type and extent of climate change has and will continue to result in highly variable localized impacts [2]. This variation is exacerbated (or mitigated) by human socioeconomic systems that are more or less capable of adapting to long-term shifts in climate. Not all human communities have the same capacity to cope with environmental change [3,4]. Consequently, a 
one-size-fits-all solution does not exist for climate change adaptation. It is therefore essential to provide policy guidance and recommendations that are geographically and socioeconomically explicit.

The North Shore of Lake Superior in Minnesota (North Shore) is a tourism-dependent region along Lake Superior whose economies are especially vulnerable to the effects of climate change (Figure 1). The region's vulnerability stems from an economy dependent upon nature-based tourism and outdoor recreation opportunities provided by hundreds of interior lakes and vast tracts of publicly-managed forests and parks, as well as privately-owned resorts, outfitter and guiding services, and other tourism-related businesses. The region is also Ojibwe homeland; three Ojibwe bands retain rights to hunt, fish, and gather in the 1854 Ceded Territory. Notable nature-based tourism and outdoor recreation destinations include the Superior National Forest, the Boundary Waters Canoe Area Wilderness, the Grand Portage Indian Reservation and Grand Portage National Monument, nearly a dozen State Forests and Parks, and a privately owned and operated ski resort. Many of the area's recreational resources are collaboratively managed, making cooperation and long-term engagement essential to both delivering high-quality experiential opportunities to recreationists and managing the region's unique environmental resources.

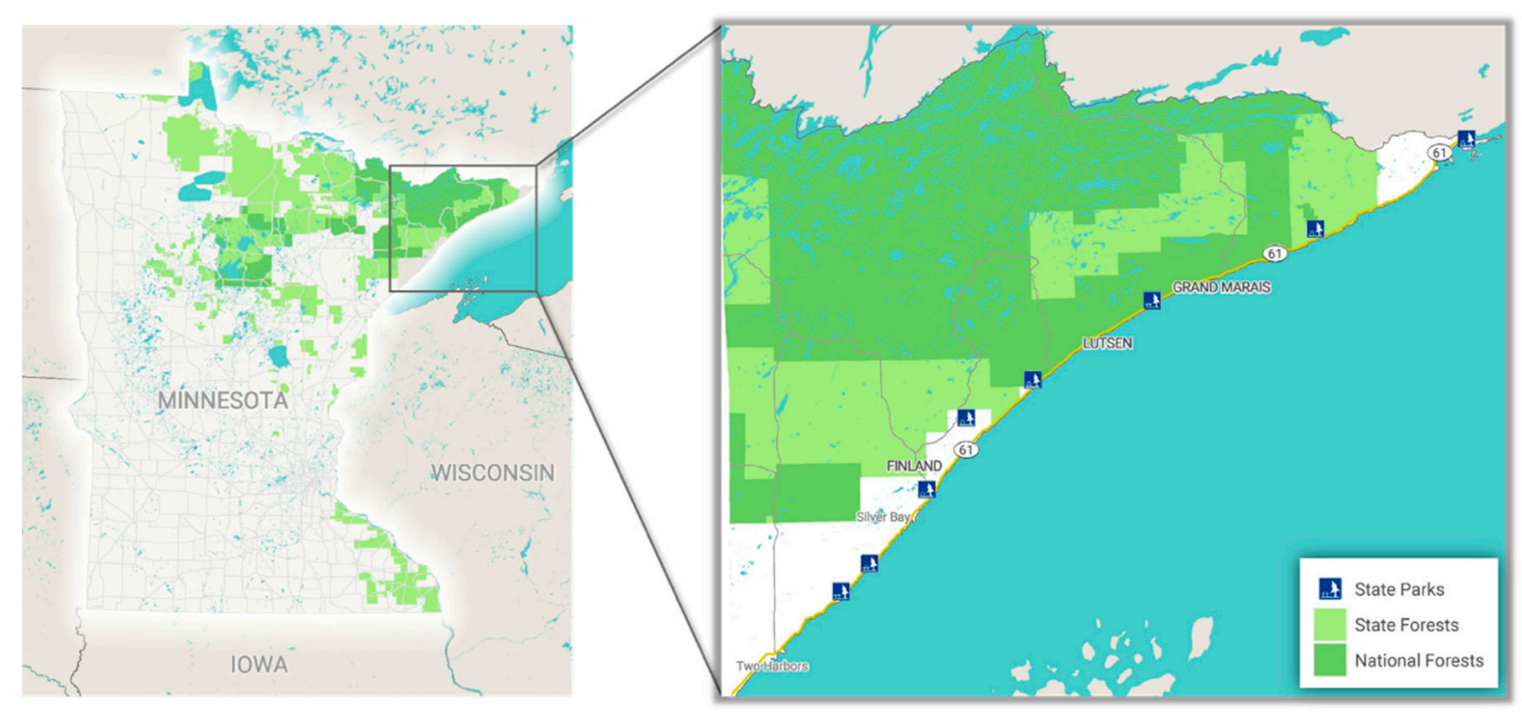

Figure 1. Minnesota's North Shore.

Mid-century climate models for the region project an increase in annual average temperatures, shifts in forest composition, increases in annual average and heavy precipitation days, and a decline in Lake Superior ice cover [5]. Climate and hydrological models using a medium emissions scenario (RCP4.5) for the region suggest that, by 2065, for the months of December, January, and February: (1) Average daily high temperatures will increase by $2.3^{\circ} \mathrm{C}$; (2) average daily ice thickness at inland lakes will decrease by $7.4 \mathrm{~cm}$; and (3) average daily snow depth will decrease by $12.7 \mathrm{~cm}$ [6]. All of these climatic or environmental changes will impact the region's recreational opportunities. For example, the lower water levels in Lake Superior have already led to boat ramps being unusable during certain times of the year. Reduced ice cover may limit the number of days recreationists can go ice fishing. Increased precipitation levels are likely to increase in-stream flow rates and may draw more tourists to the region's numerous waterfalls. Additionally, the likelihood of heavy precipitation days may impact the built infrastructure (i.e., roads, bridges, buildings, etc.) that facilitates outdoor recreation and tourism activities. Consequently, the resilience of North Shore communities will depend largely on decision makers in those communities prioritizing critical infrastructure and amenities likely to be impacted by climate change in the immediate future.

Many of the climate-related impacts to nature-based tourism and outdoor recreation along the North Shore are similar to those noted elsewhere around the world. For example, mean daily 
temperatures will likely result in increased visitation to national parks across the United States [7-9] and Canada $[10,11]$. Increased visitation is attributed to longer and warmer summer periods, which facilitates popular outdoor recreation activities like hiking and camping. Similar results have been found in Europe as well [12,13].

Despite the North Shore's vulnerability to climate change and climate's subsequent impact on environmental conditions, communities in the region have not engaged in any formal local climate change adaptation planning processes to date, with the notable exception of the 1854 Treaty Authority, which led a collaborative climate adaptation planning process in 2016 [14]. Identifying and implementing climate change adaptation policies and management options will require commitment and collaboration amongst diverse stakeholders $[15,16]$. The North Shore's economic reliance on nature-based tourism and the region's established system of collaborative planning between governments and private entities may bode well for efforts to integrate stakeholders into climate change risk assessment processes. Additionally, the identification of common risks and threats across a set of stakeholders, as is the case across the North Shore, can help facilitate effective collaborative planning activities $[17,18]$.

The goal of this study is to engage North Shore stakeholders in an exploratory application of integrating participatory geographic information systems (PGIS) into a coastal community climate risk assessment process. North Shore stakeholders, which includes resource management personnel, local residents, local government officials, and business owners, are affected by climate change either directly or indirectly through likely impacts to the region's natural resources and the outdoor recreation activities they support. Stakeholder involvement in climate change risk assessment processes allows for the co-production of science and local knowledge to develop decision support tools that are tailored to local contexts [19]. Our intent is to examine the efficacy with which PGIS can be used to assess climate-related risks to the built infrastructure and natural resources that support nature-based tourism and outdoor recreation opportunities throughout the region.

\section{Related Literature}

\subsection{Stakeholder Involvement in Climate Change Risk Assessments}

Stakeholder participation is increasingly being recommended and embedded into a variety of environmental planning processes [20]. Within climate change planning efforts in particular, stakeholder participation is believed to facilitate an equitable accounting of climate-related risks [21]. Assessing stakeholders' perceptions of local risks can be a critical step in reducing regional vulnerability to changing climatic and environmental conditions [22,23]. While some critics may discourage stakeholder engagement efforts, suggesting it contributes to a slower adoption of adaptation policies and management plans, recent research suggests engaging stakeholders can increase public support for resulting policies $[23,24]$. Increasing public support ultimately leads to more effective climate governance, where policies are perceived to be valid and are suited to stakeholders' needs.

Of the various methods developed to assess climate-related risks, many have integrated stakeholders. In a series of two articles, Lorenzoni and colleagues provided an applied case of stakeholder involvement in addressing socioeconomic change and climate vulnerability $[25,26]$. Lorenzoni et al.'s method, which they refer to as "co-evolutionary," involves using scenarios generated from downscaled climate models to assess stakeholders' perceptions of vulnerabilities to social, economic, and political systems. They applied a set of climate change indicators to capture the range and severity of potential climate-related impacts derived from the models. Lorenzoni and colleagues suggest the use of climate change indicators is effective in soliciting feedback from stakeholders. The authors argue their method captures social feedback loops in that it provides stakeholders the ability to think through how they, and their communities, would respond to alternative climate change scenarios. 
While stakeholder engagement in climate change risk assessments does not ensure complete success (i.e., the adoption of a climate change adaptation plan or policy), more successful stakeholder engagement processes tend to be: (1) Flexible; (2) iterative; and (3) interactive [27]. Stakeholder engagement is a primary goal of this study. We solicited this engagement through commonly used PGIS methods. These methods include both the use of web-based surveys to assess stakeholder-defined climate change risks and the use of an interactive focus group-based mapping exercise to do the same. Our intent was to assess the efficacy of utilizing these common PGIS methods to engage stakeholders in a climate change risk assessment process.

\subsection{Participatory Geographic Information Systems}

PGIS methods are tools and processes used to integrate spatial knowledge into policy with science [28]. PGIS methods enable community 'participants' to spatially represent their knowledge or perceptions through the various materials used in a GIS (e.g., remotely sensed images, topographic and maps). PGIS methods enable multiple stakeholders' values to be visualized and analyzed using traditional geospatial tools and analyses [29]. PGIS methods may be ideal for assessing small, nature-based, and tourism-dependent communities' climate change related risks. In their meta-analysis of PGIS studies, Brown and Kyttä [30] suggest PGIS methods are most likely to be successfully implemented in small, rural communities in which small groups of stakeholders have a large interest in, and influence over, resource management decisions.

PGIS has been used for a variety of purposes including: The demarcation of local communities and neighborhoods, the development of spatial zoning tools to manage competition and conflict, and the mapping of equity and inequalities in efforts to promote awareness and building community strength (i.e., helping communities solve collective problems) [31,32].

PGIS methods have also been used to assess communities' perceptions of local climate change vulnerabilities [33-35]. Generally, PGIS activities are integrated into larger vulnerability assessment processes and used to refine scientifically-based vulnerability assessments into more locally-relevant and contextually-meaningful assessments, maps, and decision-support tools [22]. The synthesis of local insights and scientific evidence (i.e., knowledge co-production) has a crucial role to play in climate change vulnerability assessments [36], and PGIS methods are an emerging and interactive way to engage with local stakeholders [37]. Integrating PGIS into vulnerability assessments is intended to improve both the communication between scientists and local stakeholders and the communication amongst stakeholders themselves [38]. PGIS methods in vulnerability assessments may also facilitate political empowerment, encouraging local stakeholders to proactively engage in adaptation and environmental planning processes [39].

\section{Methods}

Building a successful collaborative relationship between stakeholders and scientists depends on the delivery of actionable science that addresses the needs of local stakeholders [40]. This study utilized multiple PGIS methods to assess stakeholder perceptions of climate-related risks. These methods included a pre-survey, a focus group exercise, and a post-survey. Stakeholders consisted of county and municipal officials and planning staff, recreation and tourism industry service providers, members of tourism and commerce boards, and employees from state and federal recreation resource management agencies; all of these stakeholders lived or worked on the North Shore. Stakeholders were identified as individuals who had a high level of interest in, and influence over, local climate change adaptation planning decisions. After stakeholders were identified, we solicited their participation in one of two 2-hour focus groups dedicated to assessing North Shore communities' climate-related vulnerabilities, as well as their capacity to adapt to likely climate-related impacts. Forty-six individuals were invited to participate in the focus groups; a total of 16 consenting stakeholders accepted and served as the sample for this study (Table 1). The participants varied in their affiliation, minimizing concerns that we were omitting important perspectives or viewpoints. However, a significant limitation of our recruitment 
process was the failure to engage any tribal band members in the study. The tribes and inter-tribal organizations in the area have made important advancements in climate change risk assessment, and these perspectives would have been invaluable to the study. The participation rate would have likely been higher if we were to have held more focus groups at different locations along the North Shore, if we were to offer incentives for participation, or if the focus groups were tied to a policy (e.g., a referendum to support region-wide climate change adaptation planning) or management decision (e.g., the revision of the Superior National Forest management plan). More comprehensive details of the focus group recruitment and facilitation process are provided by Katz [41].

Table 1. Affiliations of study participants.

\begin{tabular}{lc}
\hline Affiliation & Number of Participants \\
\hline Outdoor recreation outfitter and/or guide & 5 \\
Non-profit organization & 3 \\
U.S.D.A. Forest Service & 3 \\
Minnesota Department of Natural & 2 \\
Resources & 1 \\
County tourism promotion agency & 1 \\
Food service provider & 1 \\
Lodging provider & \\
\hline
\end{tabular}

\subsection{Pre-Survey}

A map exercise was created through Qualtrics and sent electronically in a survey with other questions for participants to complete online prior to their participation in the focus group. The map portion of the instrument was composed of three nearly identical sections. In each section, participants were presented with a map of the North Shore highlighting state parks, forests, and the Superior National Forest (Figure 2).

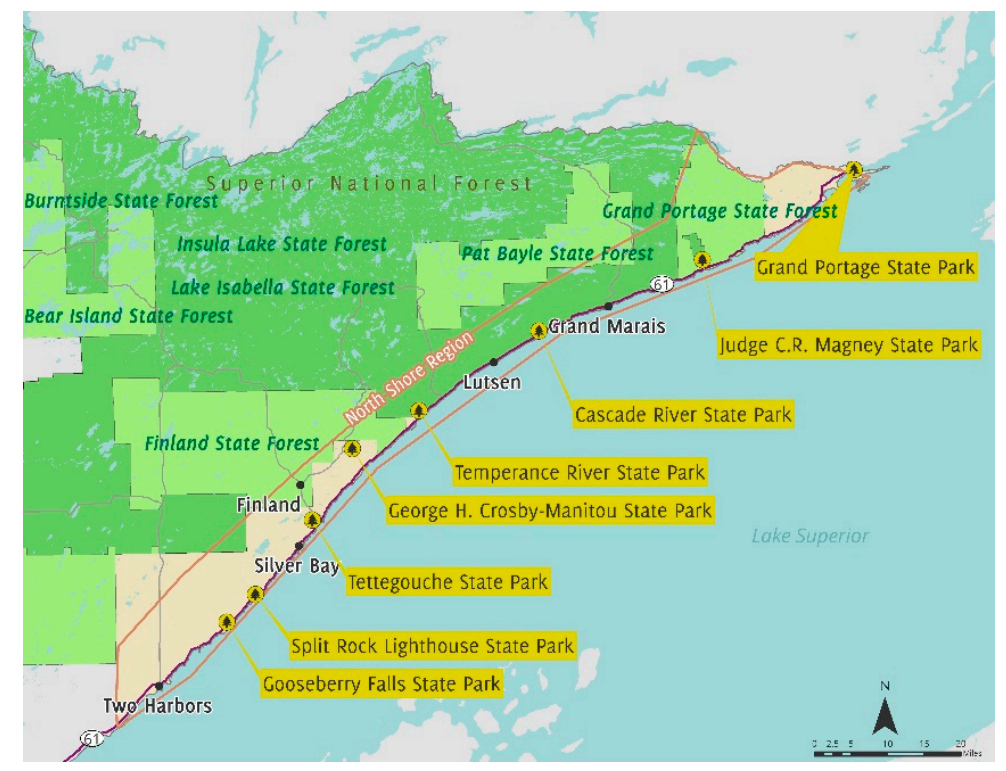

Figure 2. Map of the North Shore in the participatory geographic information systems (PGIS) pre-survey.

Survey participants were asked to identify three specific sites with built structures they believe are vulnerable to the effects of climate change by clicking the locations on the map. Following the identification of these three sites, an open-ended question asked them to describe why they believed these specific sites with built structures were highly vulnerable to the effects of climate change. In the subsequent sections, respondents were presented with the same map and with similar questions about 
two different attributes. The second section asked about specific natural amenities (e.g., forests, lakes, and waterfalls) that participants believed to be vulnerable to the effects of climate change. The third section solicited information about specific tourism and outdoor recreation destinations (e.g., trails, and resorts) that participants believed to be vulnerable to the effects of climate change. The different types of settings were not meant to be mutually exclusive- they were created to capture the broadest possible suite of tourism and outdoor recreation related resources that might be affected (or perceived to be affected) by shifting climatic and environmental conditions. We also included open-ended questions which elicited narrative descriptions of why participants believed specific built structures, natural amenities, and tourism and outdoor recreation destinations are highly vulnerable. The pre-survey instrument is available in the Supplementary File.

\subsection{Focus Group Exercise}

Consenting participants were invited to one of two focus groups to participate in an interactive PGIS exercise with project scientists. In addition to the interactive PGIS exercise, the focus group also involved a facilitated discussion with participants regarding their perceptions of climate change impacts, barriers to adaptation, existing policies, and community leaders already taking action on climate change or those who should. The first focus group was geared towards natural resource managers and involved eight participants representing the U.S.D.A. Forest Service, the State of Minnesota's Department of Natural Resources, a development agency, and two non-profit organizations (Table 1). Eight regional business owners were represented in the second focus group; the participants consisted of lodging and recreation providers, outdoor recreation outfitters and/or guides, and food service providers.

Prior to the focus groups, a web map was created through ArcGIS Online. The web map had a general topographic base layer and was absent of features. Point, polyline, and polygon features were created and placed in the legend for built structure sites, natural amenities, and recreation and tourism destinations (Figure 3). This web map was duplicated so that each focus group could start from a blank map. The web map was projected onto a wall in the focus group room, and an eBeam Edge receiver was mounted on the side of the projection surface that provided the ability to interactively manipulate the map with a stylus. The eBeam Edge receiver and stylus were wirelessly connected to a laptop through a USB drive, essentially creating an external (projected) desktop to create and edit features that are simultaneously changed, saved, and stored in an ArcGIS Online repository.

Two researchers operated the PGIS exercise. One served as a facilitator by reading the prompt and keeping notes of the participants' discussion, and the second digitized the features. An audio recorder was used to record the discussion as well. The written protocol/script was read aloud to the group, and it started with an introduction of the importance of having the participants' involvement in the analysis and then went on to provide an overview of how the exercise would work. The script is available in the Supplementary File. The mapping exercise was broken down similarly to the pre-survey, with built infrastructure sites, natural amenities, and recreation and tourism destinations each being discussed separately.

Displaying or presenting a map can serve as a prompt for a group to discuss a specific region [42]; therefore, the results from the pre-survey questions (where participants identified the three built infrastructure sites, natural amenities, and tourism and outdoor recreation destinations believed to be vulnerable to the effects of climate change) were displayed in the form of three separate geospatial density maps. A table containing recent and projected winter climate conditions (e.g., average snow depth, daily high and low temperatures, daily maximum and minimum wind chill values) in 2065 was also presented on the bottom of each map. These projections were derived from a climate model parameterized by a medium emissions scenario that was produced, along with high and low emission scenarios [6].

The facilitator guided the participants' attention to the projected climate and environmental conditions and then asked them to collaboratively, as a group, discuss and identify the top three sites they believed to be the most vulnerable to the effects of climate change. Participants were asked to 
guide the researcher digitizing their selected sites to fill in attributes about the structure and ownership types. In addition, they were asked to define the severity of risk for each site (i.e., extreme, high, moderate, or low) and risk thresholds (i.e., immediate, imminent, moderate, or low) (Table 2).

The identification of stakeholder-defined thresholds has been suggested as advantageous in climate risk assessments because they provide ownership of the outcomes and also provide a frame of reference [43]. Soliciting participants' perceptions of risk thresholds was intended to facilitate an understanding of how imminent participants perceive the risks to be while also helping them to comprehend the time scale of projected impacts. The process of the group collaboratively selecting the three most vulnerable sites and defining the attributes (severity of risk and risk thresholds) was attempted three times-once for built infrastructure sites, once for natural amenities, and once again for recreation and tourism destinations.

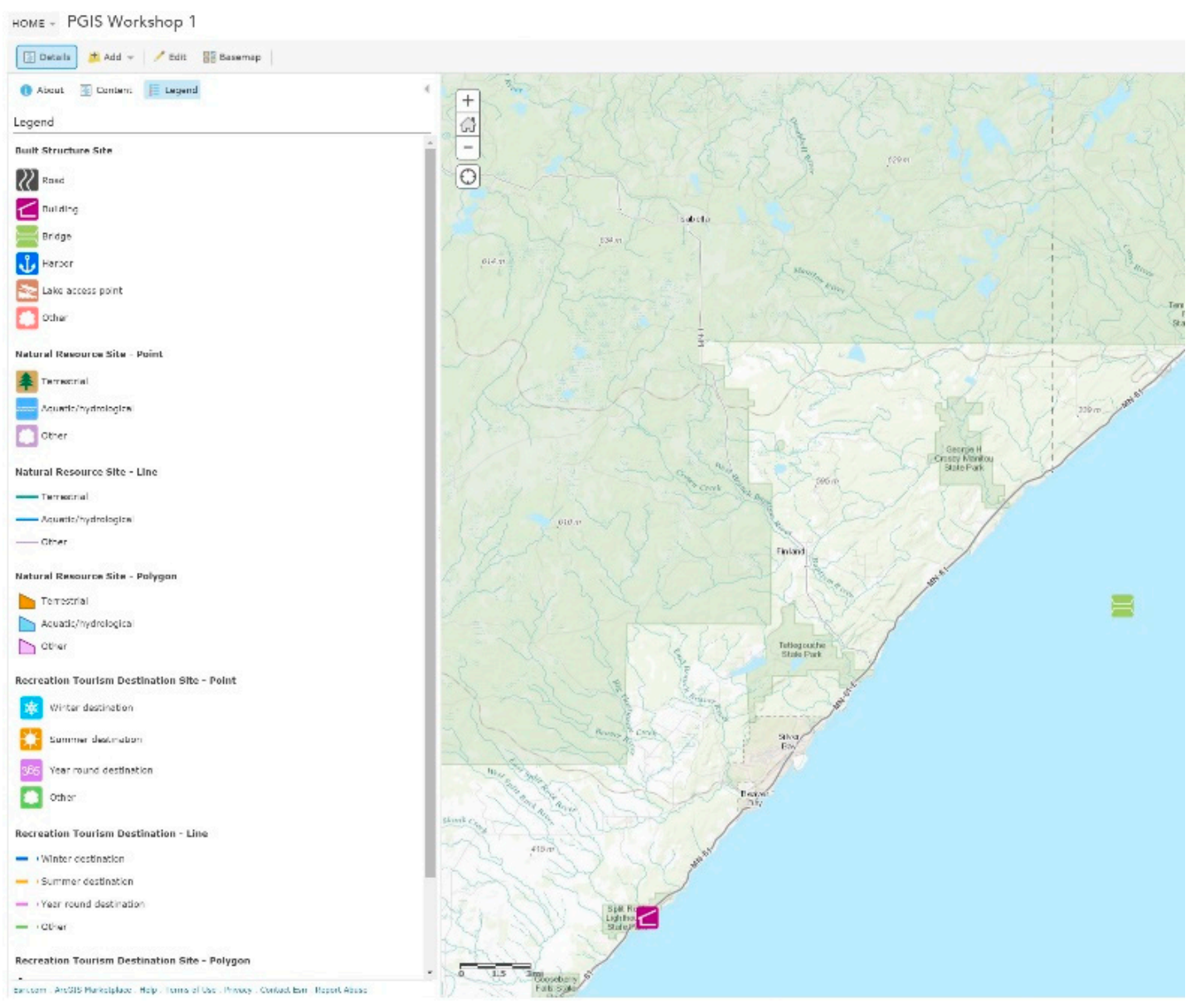

Figure 3. Screenshot of ArcGIS Online web map and legend.

Table 2. Feature attributes chosen by participants in web map.

\begin{tabular}{ll}
\hline \multicolumn{1}{c}{ Severity of Risk } & \multicolumn{1}{c}{ Risk Thresholds } \\
\hline $\begin{array}{l}\text { Extreme-The function of the structure will be completely } \\
\text { lost or rendered unusable under projected conditions. }\end{array}$ & $\begin{array}{l}\text { Immediate-Changing climatic conditions are } \\
\text { already impacting the structure. }\end{array}$ \\
\hline $\begin{array}{l}\text { High-The function of the structure will be completely } \\
\text { lost under projected conditions. }\end{array}$ & $\begin{array}{l}\text { Imminent-Changing climatic conditions are likely to } \\
\text { impact the structure by 2020. }\end{array}$ \\
\hline $\begin{array}{l}\text { Moderate-The function of the structure will be } \\
\text { moderately affected under projected conditions. }\end{array}$ & $\begin{array}{l}\text { Moderate-Changing climatic conditions are likely to } \\
\text { impact the structure by 2035. }\end{array}$ \\
$\begin{array}{l}\text { Low-The function of the structure will be minimally } \\
\text { affected under projected conditions. }\end{array}$ & $\begin{array}{l}\text { Low-Changing climatic conditions are likely to } \\
\text { impact the structure by 2065. }\end{array}$ \\
\hline
\end{tabular}




\subsection{Post-Survey}

A survey questionnaire was sent out to all participants three weeks after the focus groups were held. Similar to the pre-survey and focus groups, it was divided into three sections of the same questions in regards to built infrastructure sites, natural amenities, and outdoor recreation/tourism destinations. In each section, a table of the sites identified as highly vulnerable during the focus groups was presented.

Participants were asked to rank the severity of risk (extreme, high, moderate, or low) and indicate the perceived threshold of risk (immediate, imminent, moderate, or low) for each site; the severity and threshold categories were identical to those presented to participants in the focus groups. A final open-ended question was also included in the survey and solicited participants to express any difficulties they may have had with identifying the specific locations or assigning risk levels or thresholds to specific locations. The post-survey instrument is available in the Supplementary File. Supplementing the focus group-based exercise with individual pre- and post-surveys helps to remove the risk of bias that can arise from some individuals dominating group discussion [33].

\subsection{Data Analysis}

Data analysis differed for each PGIS method used. The pre-survey data were analyzed for spatial autocorrelation of identified points, and heat maps of identified points were created. The focus group exercise data were used to generate lists of locations discussed for different site types; identified sites were subsequently mapped. Descriptive statistics were used to analyze the majority of the post-survey data, including the percentage of responses in each of the risk severity and threshold levels. The open-ended question in the post-survey was used to help us determine the efficacy of the PGIS methods. More specifically, the open-ended question provided participants the opportunity to describe why they thought that the identification of specific highly vulnerable sites was difficult, informative, useful, etc. The open-ended responses were used to guide our interpretation of the stakeholder-generated points and descriptive statistics.

\section{Results}

\subsection{Pre-Survey}

A total of 17 responses were obtained for the pre-survey. However, only ten respondents engaged in the map questions. The density maps representing the three most vulnerable built structures, natural amenities, and outdoor recreation and tourism destinations perceived by respondents are shown in Figure 4.

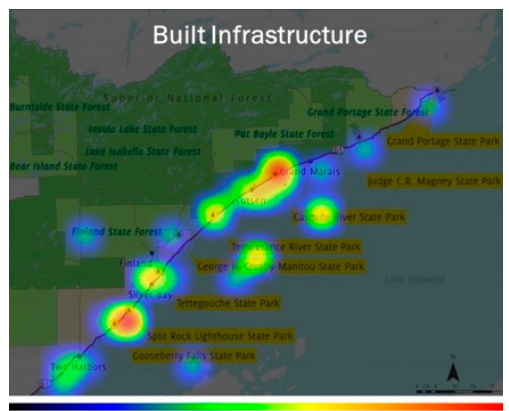

(a)

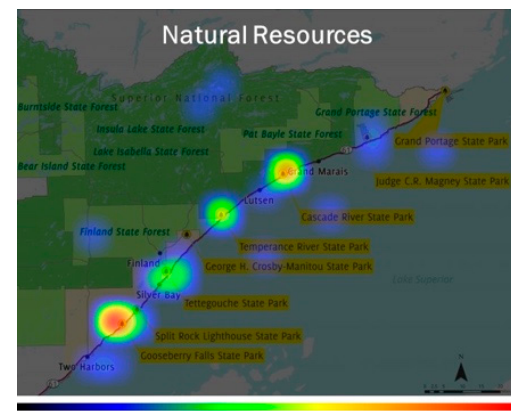

(b)

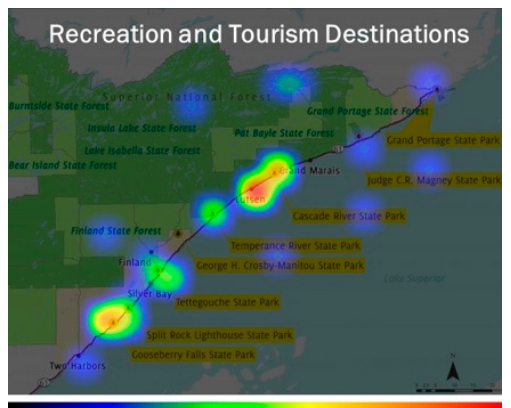

(c)

Figure 4. Density of the most vulnerable locations of (a) built infrastructure, (b) natural amenities, and (c) recreation and tourism destinations, as identified by participants.

The density maps suggest there was some confusion amongst respondents completing the pre-survey mapping exercise. Instead of clicking on the locations of these resources, a few stakeholders 
selected the callout labels of state parks in lieu of their actual geographic location. It appears that after making the mistake in the first question regarding built infrastructure, some of them became aware of the proper technique and accurately depicted the locations for natural amenities and recreation and tourism destinations. The concentration of the three sites stakeholders perceived to be the most vulnerable were in the same general locations along the shore for each type of resource. The high densities were mostly clustered around state parks and the communities of Finland, Lutsen, and Grand Marais.

An examination of the open-ended questions provided in the pre-survey soliciting descriptions of why participants believed identified sites were highly vulnerable to the effects of climate change revealed precipitation damage to state park infrastructure was a reason for multiple respondents' selections; this was in addition to fluctuating water levels affecting marinas and safe harbors. Two respondents mentioned their concern for the region's ski resort (located in Lutsen), noting it is dependent on snow. Stakeholders' responses to the open-ended questions also revealed precipitation to be a major reason they believed the natural amenities they selected to be vulnerable. Comments were centered on decreased precipitation altering the flow of waterfalls and rivers, Lake Superior water levels, and the occurrence of drought leading to more wildfires. For outdoor recreation and tourism destinations, the majority of respondents mentioned the ski resort, with the threat of shallower snow depths being the main reason for its vulnerability. In addition, increasing occurrences of wildfires were also mentioned by a few stakeholders. Collectively, responses to the open-ended questions included in the pre-survey provided a glimpse into the diverse and interrelated ways stakeholders believed the region was vulnerable to climate change. These initial insights were later expounded upon through discussions, outside of the PGIS exercise, during the focus groups. Readers interested in the full scope of the focus groups are referred to Katz [41].

\subsection{PGIS Focus Groups}

The interactive focus group-based PGIS exercises encountered similar barriers to execution during both focus groups. The prompt worked exceptionally well to solicit discussion regarding what stakeholders believed to be highly vulnerable sites. However, the prompt was not focused or structured enough to enable the successful identification of three collectively identified vulnerable sites. The first focus groups' discussion of built infrastructure surpassed the allotted time $(\sim 20 \mathrm{~min})$ for all three types of resources. Participants could not guide the facilitator to digitize three built infrastructure sites, largely because they believed large portions of the region as a whole were equally vulnerable to the effects of climate change. For example, the focus group discussion among resource management personnel centered, for some time, on the vulnerability of all secondary roads managed by the Forest Service; there are hundreds of miles of forest roads managed by the agency within the Superior National Forest. Without being able to narrow the scope of the vulnerability-ranking task down to something that could be identified and digitized in a GIS, the first focus group's discussions expanded into a productive discussion but ultimately unsuccessful mapping of the entire region's vulnerability. The focus group facilitators were unable to guide participants' discussion towards locations that could be mapped, nor could they refocus the discussion from vulnerable built structures to vulnerable natural amenities, let alone recreation and tourism destinations.

In an effort to try and ensure comparable results from the second focus group, we did not deviate from the prompts, but we were more mindful of the time. Our efforts resulted in a similar outcome from the first focus group, as the stakeholders were unable to collaboratively, as a group, identify the three most vulnerable built structures. Anticipating a similar outcome as the first focus group, the discussion facilitator prompted the second focus group to attempt to identify vulnerable natural amenities even though they had not yet identified the three most vulnerable built structures. The group's discussion revolving around vulnerable natural amenities, again, led to an extended, productive and constructive discussion that could not be successfully focused to identify and map the three sites believed to be the most vulnerable to the effects of climate change. 
Collectively, the two focus groups led to discussions on built infrastructure and natural amenities, as well as a list of the locations that were discussed by participants (Table 3). No data, spatial or non-spatial, were produced specific to the intended third section of the focus groups related to climate-related vulnerabilities to specific outdoor recreation and tourism destinations.

Table 3. The vulnerable sites identified during the focus groups.

\begin{tabular}{ll}
\hline Section 1-Built Infrastructure Sites & Section 2-Natural Amenities \\
\hline Split Rock Lighthouse & The health of the boreal forest \\
Highway 61 & Moose populations \\
Forest Service roads & Lake Superior water levels \\
Lutsen ski resort & Native insect species \\
Golf courses & Native plant species \\
Harbors and docks on Lake Superior & Native wildlife species \\
Hiking trails & Native fish species \\
Bridges & Flow rates of rivers and waterfalls \\
Storm sewer infrastructure & \\
\hline
\end{tabular}

\subsection{Post-Survey}

All of the 16 focus group participants completed the post-survey. The results for the severity of risk categories were coded from 1 (low) to 4 (extreme); larger mean values corresponded to a greater perceived risk. The risk threshold categories were also coded from 1 (low) to 4 (immediate).

The highest mean severity of risk across sites with built infrastructure corresponded to Forest Service roads (Figure 5). However, there was not a large range in the mean severity of risk scores across all built infrastructure sites; this excludes Split Rock Lighthouse, which the majority of respondents did not perceive to be as vulnerable relative to the other sites. One respondent commented on this in the open-ended question, stating he/she disagreed with the lighthouse being considered as an option, as climate wouldn't impact it. Participants also identified Forest Service roads as having the highest mean risk threshold; a large portion of respondents ranked it as an immediate risk with impacts already occurring. The extent to which respondents perceived the risks to these sites to be more immediate was similar to their overall rankings of risk severity. The risk thresholds of climate impacts to golf courses and Split Rock lighthouse were the lowest (i.e., the most distant in the future) (Figure 5). Overall, the climate-related risks to natural amenities were perceived to be greater than those to built infrastructure (Figure 6). The highest mean severity of risk was found for moose populations, followed by the health of the boreal forest. Lake Superior water levels had the lowest mean perceived severity of risk score. Mean risk threshold scores for natural amenities were very similar to mean risk severity scores (Figure 6).

The response rate on the open-ended question that we had hoped would explain difficulties encountered during the focus groups was lower than expected. Of the 16 stakeholders, seven responded when solicited to express any difficulties they may have had with identifying the specific locations in the focus groups or with rating risk severities or risk thresholds. Participants' comments revealed they had a difficult time assessing the risks in the pre- and post-survey without being provided with projected climate and environmental conditions like those that were provided during the interactive focus group exercises. Some participants also indicated that identifying the impacts to native insects, plants, or wildlife was also difficult because they had a general lack of knowledge about them. 


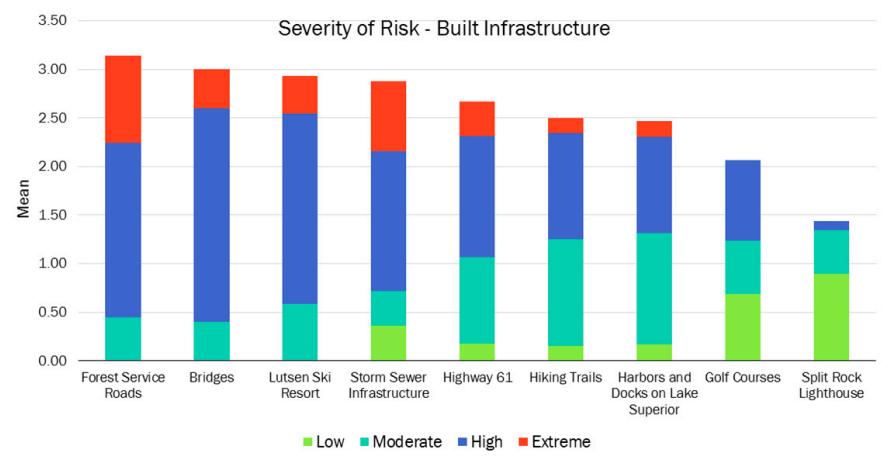

(a)

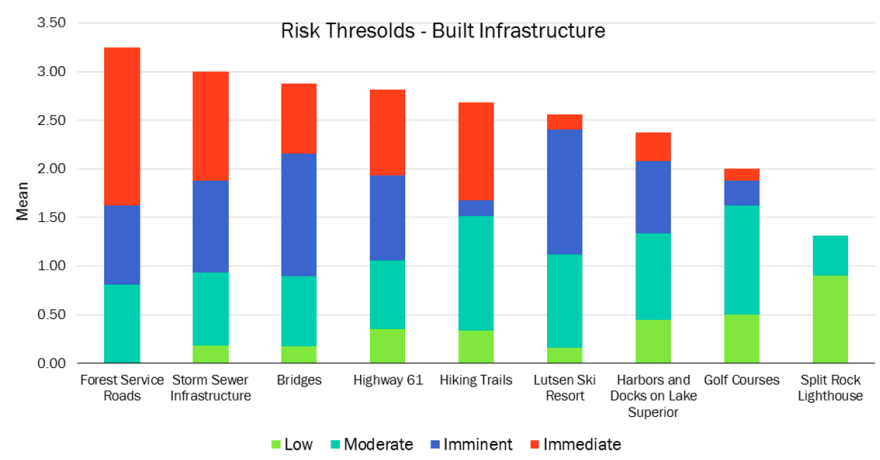

(b)

Figure 5. Mean severity of risk (a) and mean risk thresholds (b) for built infrastructure sites.

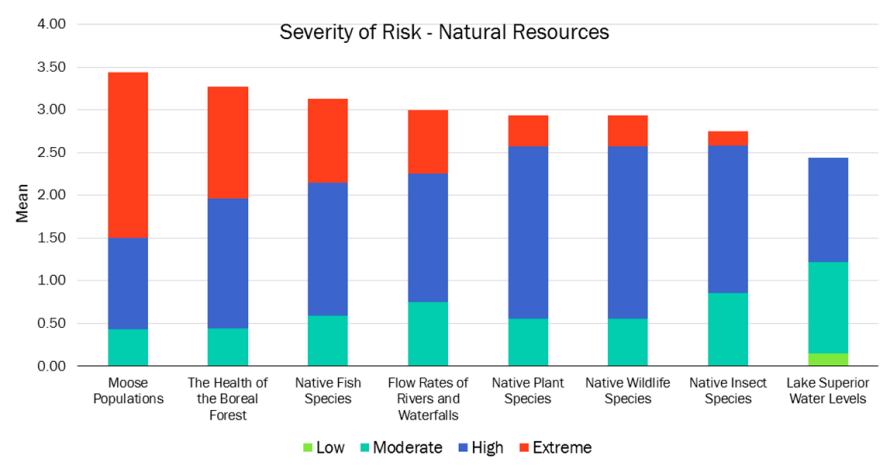

(a)

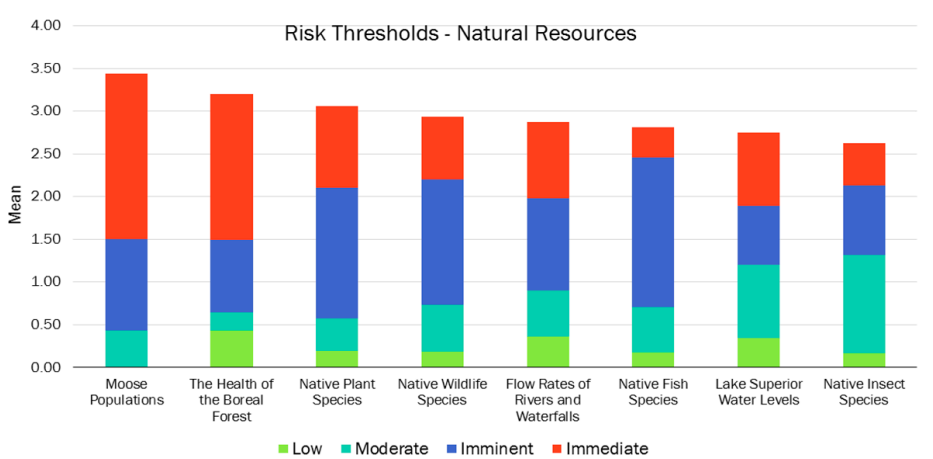

(b)

Figure 6. Mean severity of risk (a) and mean risk thresholds (b) for natural amenities. 


\section{Discussion}

There are multiple reasons to justify engaging stakeholders in climate risk assessments. Stakeholders are a source of local knowledge that can add valuable information to a risk assessment that may not have been previously considered, particularly as they are likely to be the individuals first noticing changes and experiencing local impacts [44]. This engagement often leads to community empowerment [45] and a sense of ownership and approval over resulting policy outcomes [46]. There are many ways to engage stakeholders, and utilizing multiple PGIS methods, as we did in this study, can initiate greater interest and involvement in regional climate change adaptation efforts, as has been found in other community resource management contexts [47]. Specifically, the iterative PGIS methods we deployed, consisting of a pre-survey followed by an interactive focus group discussion and a post-survey, helped to generate needed discussions about climate-related impacts to recreation and tourism resources along the North Shore. The PGIS methods also helped to facilitate a dialog between project scientists and stakeholders, suggesting the occurrence of knowledge co-production [36]. The results of the PGIS exercises, namely the heat maps of individually-identified vulnerable locations and the rated lists, while not generalizable, can be used as discussion points by project scientists and affiliated extension and outreach specialists as they continue their ongoing work to foster climate readiness among local community members, business entrepreneurs, and resource managers.

Future research and outreach efforts focused on North Shore communities could benefit from the insights gained from the PGIS exercises. For example, the Superior National Forest is currently in the process of developing a new Forest Plan, which provides general planning guidance for how the forest's natural resources and recreational opportunities are managed. The agency is actively attempting to make climate and climate-related impacts to forest resources more prevalent in the new plan. Data from the PGIS exercises revealed participants believe the forest's current network of secondary roads to be one of the most vulnerable infrastructure components across the entire North Shore region. However, transportation planning within the Forest Service rarely, if ever, considers long-term climate impacts [48]. The data yielded through the PGIS exercises suggest the agency would be wise to identify specific climate-related threats to forest roads (e.g., blow-downs caused by high-winds, fires exacerbated by drought conditions, and the increased likelihood of flooding events due to extreme precipitation events) and specific ways to lessen those threats and minimize affiliated impacts to tourism and recreation demand if trails, lakes, and other amenities are inaccessible due to actualized impacts to the secondary road system.

The process of conducting this study can also lead to more effective and efficient PGIS methods. The most notable failure in our efforts was the inability to solicit the three most vulnerable built structures, natural amenities, and outdoor recreation and tourism destinations from focus group participants. We entered the focus groups with the belief that our script was sufficiently focused enough to allow participants to identify critical resources. This clearly was not the case, as both focus groups failed to generate any spatial data via the web-based PGIS interface. Local community members and resource managers, especially those willing to provide their time to participate in a focus group, tend to be highly committed to their respective communities and local environments. These local community members' opinions, attitudes, and beliefs are grounded in years of lived-experiences. More importantly, these local community members have a strong desire to have their voices heard and integrated into resource management plans. Past research in other resource-dependent communities $[3,49]$ suggests that the commitment to local places and a strong desire to be heavily involved in resource management decisions is not isolated to the participants in the focus groups conducted for this study.

Future interactive PGIS exercises designed to generate ranked lists of critically vulnerable sites would be well suited to develop and refine highly focused questions that relate specific climate-related environmental stressors to potential vulnerabilities. For example, this may involve asking participants to consider only one projected environmental condition, such as reductions in winter snow depths or the thickness of ice on inland lakes, and to then identify specific sites that would be vulnerable to that stressor alone. Additionally, it may prove useful to have participants consider an impact of 
climate change (e.g., more intense precipitation events) and then develop conceptual models that link that impact to specific types of resources that are particularly vulnerable; this process has been used successfully in transportation planning [50]. Future vulnerability mapping research that would like to use PGIS methods may also find it helpful to remove stakeholders from the process of mapping vulnerable resources themselves. Local stakeholders may have a clear idea of what types of resources are vulnerable, as well as strong opinions as to why those resources are vulnerable. However, they may lack the knowledge or understanding of where exactly those resources are on a large landscape. For example, residents may know an animal has negatively responded to warming temperatures or changing forest composition but not be able to identify on a map where that animals' most suitable habitat is. Regardless of the methods future researchers utilize, we would strongly recommend iterative pilot testing and vetting of the interactive PGIS script with local community members, as well as ensuring adequate time for consensus-based data collection techniques. Pilot testing with non-locals is unlikely to generate the complex emotions, knowledge, and personal histories tied to local places.

In conclusion, this study set out to engage North Shore stakeholders in a climate change risk assessment process involving a PGIS workshop, as well as a pre- and post-survey. The stakeholders were heavily invested in the region; their tourism-dependent careers may have heightened their awareness of ecosystem-scale climate vulnerabilities. Though our multi-staged approach was not fully implemented as intended, the PGIS focus groups yielded some useful data and generated important discussion, while the pre- and post-survey instruments enabled the quantification of perceived climate change risk severity and thresholds for some of our intended nature-based tourism and outdoor recreation system attributes. There is room for improvement and a need for future research that attempts to use PGIS methods to identify stakeholders' perceptions of climate-related risks in nature-based tourism-dependent communities. It is crucial that future methods are developed around the specific environmental and socioeconomic context of the study area to ensure policy guidance and management recommendations meet the needs of local stakeholders.

Supplementary Materials: The following are available online at http://www.mdpi.com/2071-1050/11/12/3300/s1: Pre-survey instrument; Focus group script; post-survey instrument.

Author Contributions: Conceptualization, K.B.-M., E.S., and J.W.S; methodology, K.B.M. and J.W.S; formal analysis, K.B.M.; resources, M.D., E.S., and J.W.S.; data curation, K.B.M.; writing-original draft preparation, K.B.M.; writing-review and editing, E.S. and J.W.S.; visualization, K.B.M.; supervision, J.W.S.; project administration, M.D.; funding acquisition, M.D., E.S., and J.W.S.

Funding: This research was funded by the Minnesota Sea Grant, the National Sea Grant College Program, the National Oceanic and Atmospheric Administration, and the U.S. Department of Commerce, under award NA14OAR4170080. The statements, findings, conclusions, and recommendations are those of the author(s) and do not necessarily reflect the views of the NOAA, the Sea Grant College Program, or the U.S. Department of Commerce.

Conflicts of Interest: The authors declare no conflict of interest.

\section{References}

1. Wilby, R.L.; Fowler, H.J. Regional climate downscaling. In Modelling the Impact of Climate Change on Water Resources; Fung, C.F., Lopez, A., New, M., Eds.; Blackwell Publishing Ltd.: Chichester, UK, 2010; pp. $34-85$.

2. IPCC. Climate Change 2014: Impacts, Adaptation, and Vulnerability. Part A: Global and Sectoral Aspects. Contributions of Working Group II to the Fifth Assessment Report of the Intergovernmental Panel on Climate Change; Cambridge University Press: New York, NY, USA, 2014; p. 1132.

3. Smith, J.W.; Moore, R.L.; Anderson, D.H.; Siderelis, C. Community resilience in Southern Appalachia: A theoretical framework and three case studies. Hum. Ecol. 2012, 40, 341-353. [CrossRef]

4. Villamayor-Tomas, S.; García-López, G. The influence of community-based resource management institutions on adaptation capacity: A large-n study of farmer responses to climate and global market disturbances. Glob. Environ. Chang. 2017, 47, 153-166. [CrossRef] 
5. Pryor, S.C.; Scavia, D.; Downer, C.; Gaden, M.; Iverson, L.; Nordstrom, R. Ch. 18: Midwest. In Climate Change Impacts in the United States: The Third National Climate Assessment; Melillo, J.M., Richmond, T.C., Yohe, G.W., Eds.; U.S. Global Change Research Program: Washington, DC, USA, 2014; pp. 418-440.

6. Smith, J.W.; Seekamp, E.; McCreary, A.; Davenport, M.; Kanazawa, M.; Holmberg, K.; Wilson, B.; Nieber, J. Shifting demand for winter outdoor recreation along the North Shore of Lake Superior under variable rates of climate change: A finite-mixture modeling approach. Ecol. Econ. 2016, 123, 1-13. [CrossRef]

7. Richardson, R.B.; Loomis, J.B. Adaptive recreation planning and climate change: A contingent visitation approach. Ecol. Econ. 2004, 50, 83-99. [CrossRef]

8. Fisichelli, N.A.; Schuurman, G.W.; Monahan, W.B.; Ziesler, P.S. Protected area tourism in a changing climate: Will visitation at US national parks warm up or overheat? PLoS ONE 2015, 10, e0128226. [CrossRef]

9. Smith, J.W.; Wilkins, E.; Gayle, R.; Lamborn, C.C. Climate and visitation to Utah's “Mighty 5" national parks. Tour. Geogr. 2018, 20, 250-272. [CrossRef]

10. Scott, D.; Jones, B.; Konopek, J. Implications of climate and environmental change for nature-based tourism in the Canadian Rocky Mountains: A case study of Waterton Lakes National Park. Tour. Manag. 2007, 28, 570-579. [CrossRef]

11. Hewer, M.; Scott, D.; Gough, W.A. Tourism climatology for camping: A case study of two Ontario parks (Canada). Theor. Appl. Climatol. 2015, 121, 401-411. [CrossRef]

12. Lise, W.; Tol, R.S.J. Impact of climate on tourism demand. Clim. Chang. 2002, 55, 429-449. [CrossRef]

13. Pröbstl-Haider, U.; Haider, W.; Wirth, V.; Beardmore, B. Will climate change increase the attractiveness of summer destinations in the European Alps? A survey of German tourists. J. Outdoor Recreat. Tour. 2015, 11, 44-57. [CrossRef]

14. Stults, M.; Petersen, S.; Bell, J.; Baule, W.; Nasser, E.; Gibbons, E.; Fougerat, M. Climate Change Vulnerability Assessment and Adaptation Plan: 1854 Ceded Territory Including the Bois Forte, Fond du Lac, and Grand Portage Reservations; 1854 Ceded Territory: Duluth, MN, USA, 2016.

15. Bierbaum, R.; Smith, J.B.; Lee, A.; Blair, M.; Carter, L.; Iii, F.S.C.; Fleming, P.; Ruffo, S.; Stults, M.; McNeeley, S.; et al. A comprehensive review of climate adaptation in the United States: More than before, but less than needed. Mitig. Adapt. Strateg. Glob. Chang. 2013, 18, 361-406. [CrossRef]

16. Moser, S.C.; Ekstrom, J.A. A framework to diagnose barriers to climate change adaptation. Proc. Natl. Acad. Sci. USA 2010, 107, 22026-22031. [CrossRef] [PubMed]

17. De Lopez, T.T. Stakeholder management for conservation projects: A case study of Ream National Park, Cambodia. Environ. Manag. 2001, 28, 47-60. [CrossRef]

18. Lachapelle, P.R.; McCool, S.F.; Patterson, M.E. Barriers to effective natural resource planning in a "messy" world. Soc. Nat. Resour. 2003, 16, 473-490. [CrossRef]

19. Eikelboom, T.; Janssen, R. Interactive spatial tools for the design of regional adaptation strategies. J. Environ. Manag. 2013, 127, S6-S14. [CrossRef]

20. Reed, M.S. Stakeholder participation for environmental management: A literature review. Biol. Conserv. 2008, 141, 2417-2431. [CrossRef]

21. Reed, M.S.; Stringer, L.C. Involving stakeholders. In Land Degradation, Desertification and Climate Change: Anticipating, Assessing and Adapting to Future Change; Routledge: Abingdon, UK, 2016; pp. 152-168, ISBN 978-1-135-09431-7.

22. Downing, T.E.; Patwardhan, A.; Klein, R.J.T.; Mukhala, E.; Stephen, L.; Winograd, M.; Ziervogel, G. Assessing vulnerability for climate adaptation. In Adaptation Policy Frameworks for Climate Change: Developing Strategies, Policies and Measures; Lim, B., Spanger-Siegfried, E., Eds.; Cambridge University Press: Cambridge, UK, 2005; pp. 67-89.

23. Lemos, M.C.; Morehouse, B.J. The co-production of science and policy in integrated climate assessments. Glob. Environ. Chang. 2005, 15, 57-68. [CrossRef]

24. Few, R.; Brown, K.; Tomkins, E.L. Public participation and climate change adaptation: Avoiding the illusion of inclusion. Clim. Policy 2007, 7, 46-59. [CrossRef]

25. Lorenzoni, I.; Jordan, A.; Hulme, M.; Kerry Turner, R.; O’Riordan, T. A co-evolutionary approach to climate change impact assessment: Part I: Integrating socio-economic and climate change scenarios. Glob. Environ. Chang. 2000, 10, 57-68. [CrossRef] 
26. Lorenzoni, I.; Jordan, A.; O'Riordan, T.; Kerry Turner, R.; Hulme, M. A co-evolutionary approach to climate change impact assessment-Part II: A scenario-based case study in East Anglia (UK). Glob. Environ. Chang. 2000, 10, 145-155. [CrossRef]

27. Kirchhoff, C.J.; Carmen Lemos, M.; Dessai, S. Actionable Knowledge for Environmental Decision Making: Broadening the Usability of Climate Science. Annu. Rev. Environ. Resour. 2013, 38, 393-414. [CrossRef]

28. Dunn, C.E. Participatory GIS-A people's GIS? Prog. Hum. Geogr. 2007, 31, 616-637. [CrossRef]

29. Burrough, P.A.; McDonnell, R.A.; Lloyd, C.D. Principles of Geographical Information Systems, 3rd ed.; Oxford University Press: Oxford, UK, 2015.

30. Brown, G.; Kyttä, M. Key issues and research priorities for public participation GIS (PPGIS): A synthesis based on empirical research. Appl. Geogr. 2014, 46, 122-136. [CrossRef]

31. McCall, M.K. Seeking good governance in participatory-GIS: A review of processes and governance dimensions in applying GIS to participatory spatial planning. Habitat Int. 2003, 27, 549-573. [CrossRef]

32. Sieber, R. Public participation geographic information systems: A literature review and framework. Ann. Assoc. Am. Geogr. 2006, 96, 491-507. [CrossRef]

33. Cutts, B.B.; White, D.D.; Kinzig, A.P. Participatory geographic information systems for the co-production of science and policy in an emerging boundary organization. Environ. Sci. Policy 2011, 14, 977-985. [CrossRef]

34. Preston, B.L.; Yuen, E.J.; Westaway, R.M. Putting vulnerability to climate change on the map: A review of approaches, benefits, and risks. Sustain. Sci. 2011, 6, 177-202. [CrossRef]

35. Reichel, C.; Frömming, U.U. Participatory mapping of local disaster risk reduction knowledge: An example from Switzerland. Int. J. Disaster Risk Sci. 2014, 5, 41-54. [CrossRef]

36. Meadow, A.M.; Ferguson, D.B.; Guido, Z.; Horangic, A.; Owen, G.; Wall, T. Moving toward the deliberate coproduction of climate science knowledge. Wea. Clim. Soc. 2015, 7, 179-191. [CrossRef]

37. Brown, G.; Fagerholm, N. Empirical PPGIS/PGIS mapping of ecosystem services: A review and evaluation. Ecosyst. Serv. 2015, 13, 119-133. [CrossRef]

38. Eakin, H.; Luers, A.L. Assessing the vulnerability of social-environmental systems. Annu. Rev. Environ. Resour. 2006, 31, 365-394. [CrossRef]

39. Elwood, S. Volunteered geographic information: Future research directions motivated by critical, participatory, and feminist GIS. GeoJournal 2008, 72, 173-183. [CrossRef]

40. Lindenfeld, L.; Smith, H.M.; Norton, T.; Grecu, N.C. Risk communication and sustainability science: Lessons from the field. Sustain. Sci. 2014, 9, 119-127. [CrossRef]

41. Katz, K.L.M. Place Meanings and Climate Change Vulnerability: Nature-Based Recreation and Tourism Community Leaders Contemplate Change; University of Minnesota: St. Paul, MN, USA, 2017.

42. Hung, H.-C.; Chen, L.-Y. Incorporating stakeholders' knowledge into assessing vulnerability to climatic hazards: Application to the river basin management in Taiwan. Clim. Chang. 2013, 120, 491-507. [CrossRef]

43. Jones, R.N. An environmental risk assessment/management framework for climate change impact assessments. Nat. Hazards 2001, 23, 197-230. [CrossRef]

44. Tonmoy, F.N.; Rissik, D.; Palutikof, J.P. A three-tier risk assessment process for climate change adaptation at a local scale. Clim. Chang. 2019, 153, 539-557. [CrossRef]

45. Duval-Diop, D.; Curtis, A.; Clark, A. Enhancing equity with public participatory GIS in hurricane rebuilding: Faith based organizations, community mapping, and policy advocacy. Community Dev. 2010, 41, 32-49. [CrossRef]

46. Moser, S.C.; Ekstrom, J.A. Taking ownership of climate change: Participatory adaptation planning in two local case studies from California. J. Environ. Stud. Sci. 2011, 1, 63-74. [CrossRef]

47. Jankowski, P. Towards participatory geographic information systems for community-based environmental decision making. J. Environ. Manag. 2009, 90, 1966-1971. [CrossRef]

48. Turner, T. Roadless Rules: The Struggle for the Last Wild Forests; Island Press: Washington, DC, USA, 2009. 
49. Davenport, M.A.; Anderson, D.H. Getting from sense of place to place-based management: An interpretive investigation of place meanings and perceptions of landscape change. Soc. Nat. Resour. 2005, 18, 625-641. [CrossRef]

50. Bollinger, L.A.; Bogmans, C.W.J.; Chappin, E.J.L.; Dijkema, G.P.J.; Huibregtse, J.N.; Maas, N.; Schenk, T.; Snelder, M.; van Thienen, P.; de Wit, S.; et al. Climate adaptation of interconnected infrastructures: A framework for supporting governance. Reg. Environ. Chang. 2014, 14, 919-931. [CrossRef] 